\title{
Psychosocial Factors in Fibromyalgia: A Qualitative Study on Life Stories and Meanings of Living with Fibromyalgia
}

\author{
Paula J. Oliveira and Maria Emília Costa \\ Psychology Centre of University of Porto, \\ Faculty of Psychology and Educational Sciences, University of Porto, \\ Portugal
}

\section{Introduction}

Fibromyalgia (FM) is defined by the American College of Rheumatology (ACR) 1990 classification criteria as a syndrome in which an individual is required to have both a history of chronic widespread pain and the presence of, at least, 11 of 18 tender points (Wolfe et al., 1990). However, additional symptoms such as sleep disorders, fatigue, and psychological distress are also common in clinical practice (Blotman \& Branco, 2007; Wilke, 2009) which has contributed over time to questioning if tender points would be the most appropriate measure to capture the essence of FM (Wilke, 2009). In 2010, Wolfe et al., proposed the ACR preliminary diagnostic criteria for FM including two variables that best defined FM and its symptom spectrum: the widespread pain index (WPI) and the symptom severity scale (SS scale). The WPI is a measure of the number of painful body regions and the SS scale assesses cognitive problems, unrefreshed sleep, fatigue, and somatic symptoms. The authors combined the WPI and the SS scale in order to recommend a new case definition of FM: (WPI $\geq 7$ AND SS $\geq 5$ ) OR (WPI 3-6 AND SS $\geq 9$ ); moreover, the symptoms have to be present at a similar level for at least 3 months and the patient does not have a disorder that explain the pain (Wolfe et al., 2010). In terms of gender prevalence, FM is more common among women between 20 and 50 years (Blotman \& Branco, 2007).

Although the exact etiology and pathogenesis of FM are still unknown there is evidence that psychosocial factors could play an important role. In fact, FM has been conceptualized within biopsychosocial perspectives, in which physiological, psychological, and social factors are considered as interacting in different ways and at different stages. In a review article, Eich et al. (2000) evaluated the role of psychosocial factors in the development of FM supporting that psychosocial factors can be relevant at different etiological levels and can be classified into predisposing, triggering, and stabilising/"chronifying". On the other hand, Van Houdenhove and Egle (2004) conceptualized stress as playing a key role in the pathogenesis of FM, placing emphasis on the relationships among adverse life experiences, stress regulation, and pain-processing mechanisms. One year later, the authors highlighted, from an etiologic point of view, studies concerning the role of adverse life events, personality and lifestyle factors, post-traumatic stress, and negative childhood experiences (Van Houdenhove et al., 2005). Thus, the proposed integrative biopsychosocial models 
consider the role of the individuals' life events in the development of the syndrome. In a related conceptualization, Quartilho (2004) proposed that FM should be understood both in a cross-sectional and a longitudinal perspective. In a retrospective qualitative study with FM patients, the author has found empirical support for the classification of predisposing, triggering, and perpetuating factors, identifying specific categories within each one. Therefore, previous theoretical and empirical contributions highlight that psychosocial factors in FM could be classified as predisposing, triggering, and perpetuating; moreover this classification requires both a retrospective and a cross-sectional perspective in order to understand it, given the distinct periods of time wherein vulnerabilities can be identified. More specifically, predisposing factors include adverse events during life-time contributing to individual vulnerability due to their long-lasting psychological effects. These factors are not necessarily causal and include previous adverse life events, in general, and physical and emotional traumas, in particular. These conditions can contribute to further manifestations of low self-esteem, low self-efficacy, and negative affect which increases the risk of dysfunctional life styles and unsatisfying relationships (Eich et al., 2000; Van Houdenhouve $\&$ Egle, 2004). On the other hand, triggering factors are those preceding the pain onset and causing it directly (Eich et al., 2000), such as loss of meaningful relationships, critical changes in life conditions, and severe physical diseases. Although triggering factors are usually well-described in terms of a specific time and situation, they can also comprise multiple situations reflecting an extended period of physical and psychosocial stress (Van Houdenhove \& Egle, 2004). Lastly, perpetuating factors can help to explain the maintenance of FM, once arisen; these factors can work against the natural remission or can lead to a chronic state of illness by increasing the frequency or intensity of the symptoms. Possible perpetuating factors in FM can be depression, anxiety, worrying, catastrophic thinking, and dysfunctional health-care seeking behaviour. Thus, FM is conceptualized as the end stage of an accumulation of biological and psychosocial vulnerability factors, over time. The successive emergence of those factors promoting the individual's vulnerability ends at the appearance of the first symptoms establishing an irreversible stage (Eich et al., 2000; Quartilho, 2004; Van Houdenhove \& Egle, 2004; Van Houdenhove et al., 2005). Therefore we stress the relevance of considering life stories of FM individuals in order to identify key moments of biological and psychosocial deregulation which can promote the further development of the syndrome and its maintenance once arisen. Moreover, the lack of empirical studies performed in this domain (Quartilho, 2004) support the relevance of finding empirical support for theoretical conceptualizations (Eich et al., 2000; Van Houdenhove \& Egle, 2004), namely concerning identification of specific dimensions inside each of the major categories: predisposing, triggering, and perpetuating factors.

On the other hand, and based in Quartilho (2004), we support the relevance of proposing an integrated comprehension of FM experience considering both a longitudinal (life stories) and a cross-sectional perspective (meanings of living with FM in the present time). This combined perspective can be achieved through patients' narratives (Quartilho, 2001a, 2001b; Yardley, 1997). In fact, emphasizing a meaning-based perspective for comprehension of FM, various qualitative studies have been useful in order to understand the psychological representations of patients concerning their condition, as narrated by their own words (e.g. Sim \& Madden, 2008). One of the particularities that can be found in FM patients is the narrated importance of obtaining a clinical diagnosis and, thus, an external validation of their suffering given the absence of "visible" symptoms to others (e.g. Cunningham \& Jillings, 2006; Hellström et al., 1999; Schaefer, 1995; Undeland \& Malterud, 2007). Moreover, 
several studies have shown that FM has impact on different life contexts of individuals living with such a chronic condition (e.g., Aïni et al., 2010; Arnold et al., 2008; Asbring, 2001; Cunningham \& Jillings, 2006; Söderberg \& Lundman, 2001), and some of them have stressed specific dimensions, such as professional life (Gauer, 2009; Liedberg \& Henriksson, 2002), couple relationship (e.g. Schmidt, 2008), and sexual experience (e.g. Garcia-Campayo \& Alda, 2004). Furthermore, the finding and evolution of adaptive coping strategies in the context of FM tend to assume an important role in living with FM (e.g. Cunningham \& Jillings, 2006; Hellström et al., 1999; Schaefer, 1995, 1997; Söderberg \& Lundman, 2001). Another meaning-making process identified in FM patients' narratives is related to the perceived control over symptoms (e.g., Asbring, 2001; Hellström et al., 1999), which can range from perceived absence of control to a perceived total control over symptoms. The perceived control dimension has been highlighted as being associated to positive physical and emotional health outcomes (e.g. Hagger \& Orbell, 2003; Scharloo \& Kaptein, 1997) and more adaptive coping strategies (Joyce-Moniz \& Barros, 2005) in chronic patients. However, as far as we know, there are no qualitative studies which have assessed the link between perceived control meanings and narrated life stories. Thus, one of the innovations of the present study will be to answer the following research question: Are the perceived control meanings associated to patients' life stories and coping strategies, as well?

Considering the previous theoretical and empirical contributions the aims of the present study are:

a. To access the life stories of patients with FM in order to identify specific psychosocial factors which are considered to have a predisposing, triggering, and perpetuating role in FM;

b. To identify the meanings associated to living with FM at the present time;

c. To explore relationships among perceived control meanings and patients' life stories as well as coping strategies.

\section{Method}

\subsection{Sample and study design}

Twenty female who met the ACR criteria for the classification of FM (Wolfe et al., 1990) were recruited through Myos - Portuguese National Association against Fibromyalgia and Chronic Fatigue Syndrome. Participants were excluded if they had significant physical or psychiatric comorbidity (namely severe pain not related to FM and psychotic disorders) that might have interfered with their experience of, or ability to talk about, FM. Purposive sampling ensured the inclusion of individuals differing in various sociodemographic variables in order to maximize the range of the narrated experiences. The sample predominantly consisted of "married" individuals $(80 \%)$, but included "single" and "divorced" persons, as well. In terms of education "elementary school" and "graduate level" were the most common levels, each one with a sample representation of $30 \%$. Regarding the employment status, $55 \%$ of the sample were "currently employed", followed by "retired" $(25 \%)$ and "unemployed" $(20 \%)$ persons. Mean symptom duration was 16 years and the mean time elapsed since diagnosis was 4 years.

\subsection{Procedure}

First, approval of the study protocol and procedures was obtained from Direction of Myos. Then, participants gave their written informed consent after having received 
detailed information about the study and having being assured of anonymity and confidentiality of their interview responses. Next, personal tape-recorded interviews were conducted with each participant. The interviews were about 60 to 150 minutes in length and took place either in the researcher's office or in the participant's home. The data of the current study were collected within the scope of the PhD. dissertation of the first author (Oliveira, 2008).

\subsection{Measure (semi-structured interview guide)}

A semi-structured interview guide was used in order to collect information concerning life stories of FM patients, as well as meanings associated to the experience of living with FM. The first section of the guide aimed to explore participants' life stories according to their own personal narrative. The second section of the guide included questions directed to (i) the experience of having the first symptoms until the moment when participants received a diagnosis of FM; (ii) the impact of having FM in the current time; (iii) used ways of dealing with FM; (iv) the meaning-making processes underlying: the believed causes that participants felt to contribute to the predisposition, triggering, and perpetuating of FM; the perceived control over FM; and the future perspectives. Questions were initially open-ended to guarantee participants were not biased by the topics of interest; direct questions were only used when relevant topics did not arise in response to the open-ended questions. This methodology has given participants the opportunity to mention spontaneously any relevant domains not previously included in the interview guide.

\subsection{Data analysis}

Interviews were audio-taped and transcribed with all participant identifiers removed during transcription. Accordingly to the theoretical principles of grounded theory a data analysis was performed (Strauss \& Corbin, 1998), using the QSR NVivo7 software. Each interview was read through several times in order to get a sense of their content. Then, coding of quotes involved assigning appropriate codes to patient statements determined by the underlying concept. That is, textual units were identified and categorized with the aim of constructing a list of categories for each interview. The emerging categories were compared to identify those commonly occurring among the interviews. This allowed us to develop an iterative coding scheme, driven by the participants' experience. After that, a final list of categories and subcategories were constructed. Trustworthiness of the data was addressed through close adherence to the method of grounded theory. Consensus about the process of analyzing data was reached through extensive discussion between the researchers.

\section{Results and discussion}

\subsection{Life stories of individuals living with FM}

Findings from our thematic analysis of the life stories of individuals with FM support previous conceptualizations of predisposing, triggering, and perpetuating factors in origin and maintenance of FM (Eich et al., 2000; Quartilho, 2004; Van Houdenhove \& Egle, 2004; Van Houdenhove et al., 2005). Moreover, our results advance knowledge in this domain by identifying specific factors within these major categories. Table 1 identifies the categories and respective subcategories that have emerged from the life stories, as well as their prevalence in our sample. 


\begin{tabular}{|c|c|c|}
\hline Predisposing factors & Triggering factors & Perpetuating factors \\
\hline $\begin{array}{l}\text { Adverse life events }(75 \%) \\
\text { Significant losses }(65 \%) \\
\text { Personality traits }(45 \%) \\
\text { Physical and/or verbal violence } \\
(45 \%) \\
\text { Family conflicts }(45 \%) \\
\text { Excessive striving for high } \\
\text { achievement at work (35\%) } \\
\text { Emotional neglect ( } 35 \%) \\
\text { Nuclear family psychosocial } \\
\text { problems (35\%) } \\
\text { Job dissatisfaction }(30 \%) \\
\text { Early assumption of } \\
\text { responsibility (30\%) } \\
\text { Unsatisfying relationships (30\%) } \\
\text { History of sexual abuse }(10 \%) \\
\text { Compensatory overactive } \\
\text { lifestyles (10\%) }\end{array}$ & $\begin{array}{l}\text { Not identified }(40 \%) \\
\text { Extended period of } \\
\text { physical and/or } \\
\text { psychosocial stress }(35 \%) \\
\text { Traumatic physical } \\
\text { experience }(20 \%) \\
\text { Traumatic emotional } \\
\text { experience }(20 \%) \\
\text { Painful injury }(15 \%)\end{array}$ & $\begin{array}{l}\text { Family relationships }(45 \%) \\
\text { Sleep disturbances }(35 \%) \\
\text { Catastrophic thoughts }(30 \%) \\
\text { Depressive/anxious } \\
\text { symptomatology }(30 \%) \\
\text { Social withdrawal }(30 \%) \\
\text { Low illness acceptance }(25 \%) \\
\text { Dysfunctional health care- } \\
\text { seeking behaviour }(25 \%) \\
\text { Extended period of } \\
\text { physical/psychosocial stress } \\
\text { (15\%) } \\
\text { Somatic vigilance }(15 \%)\end{array}$ \\
\hline
\end{tabular}

Table 1. Predisposing, Triggering, and Perpetuating factors identified in life stories of FM patients and prevalence of each one in the sample.

In the "predisposing factors" category, 13 subcategories were identified reflecting physical, psychological, and social aspects which can promote individual vulnerability across the time. It is worth noting that in the entire sample (20 participants) it was possible to identify the presence of several specific predisposing factors whose prevalence varied considerably among the participants (2 to 13). This result support the assumption that not all FM patients present extremely adverse life stories and the presence of protective factors can be useful to further individual well-being (Van Houdenhove \& Egle, 2004). More specifically, $75 \%$ of the sample narrated "adverse life events" whose recall triggered, even at the present time, powerful negative emotions. Moreover, a diversity of subcategories was identified as potentially promoting individual vulnerability due to their long-lasting psychological effects (Eich et al., 2000; Quartilho, 2004; Van Houdenhove \& Egle, 2004; Van Houdenhove et al., 2005). More specifically, some of those subcategories reflect a more intrapersonal level, such as "significant losses", "personality traits", "excessive striving for high achievement at work", "job dissatisfaction", "early assumption of responsibility", "compensatory overactive lifestyles"; while others assume a more clear position in interpersonal context, namely "physical and/or verbal violence", "family conflicts", "emotional neglect", "nuclear family psychosocial problems", "unsatisfying relationships", and "history of sexual abuse". 
Regarding "triggering factors", results moderately supported its role in the appearance of the first FM symptoms. In fact, in $40 \%$ of our sample any event associated to the appearance of the symptoms was identified. However, a considerable percentage of the sample $(35 \%)$ narrated an "extended period of physical and/or psychosocial stress" before the manifestation of first FM symptoms. Factors associated to biological deregulation seemed to assume an important role as well, such as, the occurrence of a "traumatic physical experience" (20\%) and "painful injury" (15\%). And, to a lesser degree, "traumatic emotional experiences" were also mentioned. These results support theoretical conceptualizations of the role of the stress, in it physical and psychological dimensions, as trigger of FM syndrome (Van Houdenhove \& Egle, 2004).

In "perpetuating factors" category, it is worth noting that the majority of sample presented a wide variety of biological, psychological, and social factors negatively associated with health-related quality of life, thus potentially intensifying the experience of FM (Eich et al., 2000; Quartilho, 2004). More specifically, "family relationships" (45\% of the participants are included here) were identified as likely having a deleterious effect on perceived health status. Family conflicts, lack of affectionate relationships, dysfunctional couple relationship, negative manifestations of spouse, and conflicts are perceived as being associated to severe depressive symptoms by participants. This result supports the importance of family relationships on individual well-being (Quartilho, 2001b). At an intrapersonal level, dimensions as "sleep disturbances", "catastrophic thoughts", "depressive/anxious symptomatology", "low illness acceptance" and "somatic vigilance" emerge as potential factors of aggravating FM symptoms, which gives empirical support to previous theoretical conceptualizations (Eich et al., 2000; Quartilho, 2004; Van Houdenhove \& Egle, 2004; Van Houdenhove et al., 2005). Furthermore, "social withdrawal", "dysfunctional health care-seeking behaviour" leads us to the inclusion of individual in their social context. Consistent with the theoretical model of Van Houdenhove and Egle (2004), an "extended period of physical/psychosocial stress" was also present.

Our results are thus compatible with perspectives that development and maintenance of FM can be associated to the role of the stress; a biological predisposition interacting with an unfavourable psychosocial context could create conditions to the appearance and perpetuation of FM in individuals' life.

\subsection{Meanings of individuals living with FM}

Concerning the meanings of individuals living with FM in the present time, four categories have emerged. More specifically, the patients were involved in great efforts to get their illness confirmed until FM had been diagnosed (Finding a diagnosis: fibromyalgia) and, presently living with FM is experienced as bringing several changes to the participants' life (A changed life); these patients seem to make use of different strategies to cope with those changes (Coping with fibromyalgia), as well as develop new perspectives about themselves and surrounding contexts (Perspectives about a new reality).

Regarding the first category "Finding a diagnosis: fibromyalgia" it can be noted that this was a lengthy process for most participants (the average time for obtaining a diagnosis after the appearance of the first symptoms was nearly 12 years). In the early (pre-diagnosis) stage, when their "perceived first symptoms" are still unknown, patients tended to attribute them 
different degrees of severity. This experience led to "health care seeking behaviours" in order to identify what is happening to them. However, the successive consultations, normal results of various medical tests, and the absence of a diagnosis tended to be accompanied by "negative feelings" such as sadness, anger, and questioning of their own mental health. As patients do not have a label for their situation, "family and work colleagues" tend to be suspicious of their complaints. For all these reasons, people tended to describe the moment they "get the diagnosis" with feelings of relief. This entire process can be, at least partially, theoretically explained by self-regulation model of Howard Leventhal (1980, 1997). In fact, the dissonance between symptom perception and social/medical messages, added to incomprehension of significant ones, promote the individuals' difficulty on the process of creating cognitive representations which are needed for the self-regulation processes in illness. Therefore, it is understandable the occurrence of negative emotional responses during this process and positive ones (mainly, relief) when obtaining a clinical diagnosis. Thus, the diagnosis can help to eliminate the initial dissonance between symptom perception and social messages.

Concerning the category "A changed life", it is related to the perception of participants in the impact of FM on their lives, particularly in terms of "disturbing symptoms", "daily activities", "marital relationship", "sexual life", "family life", "professional life", and "social life" (Table 2). As stated in previous studies, a wide range of life contexts seems to have been affected by the presence of FM (Aïni et al., 2010; Arnold et al., 2008; Asbring, 2001; Cunningham \& Jillings, 2006; Söderberg \& Lundman, 2001). Considering the high impact of FM in patients' lives, these context-related impacts would presumably exert a negative influence on the health-related quality of life; however, the narrated impact of FM in most situations was associated to a movement towards higher levels of adaptation.

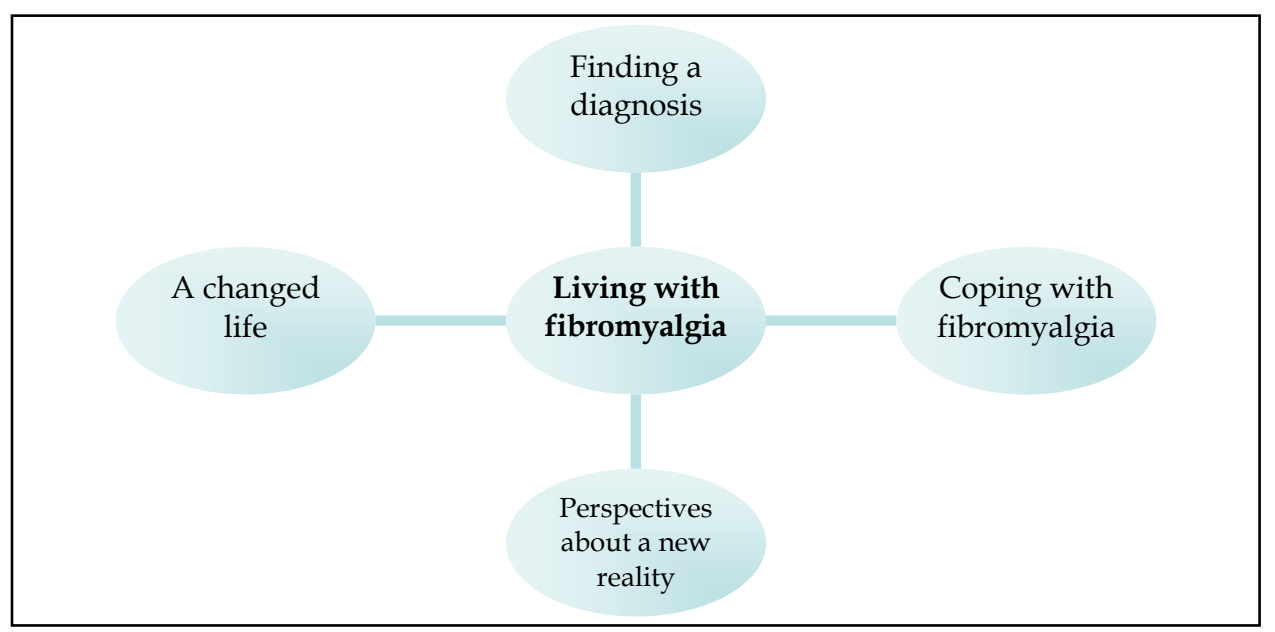

Fig. 1. Meanings of living with fibromyalgia 


\section{"A CHANGED LIFE"}

\section{Disturbing symptoms}

"The most debilitating were, undoubtedly, the cognitive symptoms. Considering the personal, social, and professional areas I think that was the fatigue; not being able to stand up, having to lie down a couple of times a day in order to be minimally lucid and be able to stand on my feet. And, then, the pain." (I1, 40 years old)

\section{Daily activities}

"... at home I don't have that vitality, that strength I had some time ago; now, I don't have it. I say this with great sadness and sometimes tears run down my face because I'm not anymore the person used to be." (I6, 51 years old)

\section{Marital relationship}

"... each day we could move forward, although we permanently felt this weight, we were closer to each other. Step by step, closer. After these years, after the diagnosis, and having realized that all this happened, we had also gone through a process of knowing each other. " (I3, 32 years old)

\section{Sexual life}

"My husband understands me... in the area of sexuality (FM) affected me a lot, but now it does not affect me so much... when I'm not able, I am not, but when I am, I express myself and my husband knows" (I10, 51 years old)

\section{Family life}

"I've always felt their support; with them I was able to put up with my pain. Last year when I was very ill they gave me a tremendous strength, really, and when I feel worse they support me and help me several times ... "(I17, 45 years old $)$

\section{Professional life}

"... when I am at work the first two hours go well, but then I start to get tired, sweating, having body aches all over; so I get very anxious and I feel that I can no longer work, but I have to work...I work four hours each day and I have to work, but sometimes I get angry. "(I14, 48 years old)

\section{Social life}

"In the past, I was able to find time for having fun, going to the movies, going for walks with friends, going to parties; now I'm not capable of it. I either do something or something else. "(I7, 46 years old)

Table 2. Subcategories of category "A changed life" reflecting the impact of FM in patients lives. 
Concerning "disturbing symptoms", although pain was the most mentioned, other symptoms were also stated, such as cognitive disturbance, sleep disorders, and depressive symptoms. This result is in accordance to previous studies developed with rheumatic patients (e.g. Pimm, 1997) and reflects the range of symptoms that can be presented by FM patients (Blotman \& Branco, 2007; Wilke, 2009; Wolfe et al., 2010). In terms of "daily activities", Söderberg and Lundman (2001) have shown that patients reported a decrease in level of activities (after the occurrence of FM) being associated to adjustment and emotional problems (Asbring, 2001; Söderberg \& Lundman, 2001) which is supported by the current data. However, individuals in the present study also have shown ways of facing difficulties revealing adjustment to felt limitations. Regarding "marital relationship", as supported by previous studies (Asbring, 2001; Schmidt, 2008; Söderberg et al., 2003), FM can be associated with either the weakening or strengthening of the relationship. Our results have supported the role of social support, comprehension, trust, and conflict management as important variables in this process. Also in the context of the romantic relationship, the "sexual life" was considerably impacted by FM as supported by previous literature (Garcia-Campayo \& Alda, 2004; Söderberg \& Lundman, 2001; Söderberg et al., 2003). Our results have highlighted pain as one of the most disabling symptoms in sexual activity, affecting both sexual desire and satisfaction. Although the avoidance of sexual activity due to FM was found, it was also noted that communication with the partner and coping strategies directed to sexual dimension were crucial in the process of dealing with felt difficulties. Turning now to the category of "family life", it is worth noting that our results have shown that social support, comprehension, and trust tend to be magnified or decreased due to FM. Moreover, the redefinition of roles inside the family is common and the family rituals are modified in order to respond better to patients' needs. Söderberg and Lundman (2001), as well as Söderberg et al. (2003), have found similar results in this dimension. Concerning "professional life", our results have shown associations between FM and lows levels of productivity and difficulties in following rigid schedules. Moreover, when FM contributed to abandoning active life this situation was experienced as emotionally disturbing (Asbring, 2001; Liedberg \& Henriksson, 2002). As stated by Liedberg and Henriksson (2002), and supported by our results, the matching of workplace conditions to individuals' needs can promote the maintenance of the posts for them. It was also found that the attitude of colleagues and employers can vary considerably from accepting to rejecting. Regarding "social life", results have shown a decrease of social contacts and a low willingness to have them. However, distrust and lack of understanding by friends was felt only in a small percentage of our sample; previous studies have shown a different pattern wherein unfavourable attitudes from friends were frequently reported (Söderberg \& Lundman, 2001; Söderberg et al., 2003). Thus, our results suggest a previous higher quality relationship with friends in our sample.

Regarding "Coping with fibromyalgia", we have found a common adoption of "traditional therapeutic strategies" used in the treatment of FM (specifically, pharmacological treatment, psychotherapy, physiotherapy, and physical exercise) as well as "complementary/alternative therapeutic strategies" (namely, acupuncture, reiki, and shiatsu). Finally, it is also usual for patients to adopt "individual strategies of coping" (cognitive and behavioural) in order to handle the situation in their daily lives. Concerning traditional therapeutic strategies, pharmacological treatment is the most used by our participants with a perceived moderate degree of efficacy; moreover, complementary 
therapeutic strategies are also used (Cunningham \& Jillings, 2006; Schaefer, 1997). In our sample, participants tend to use various strategies simultaneously, but each one use a specific combination pattern. This aspect gives support to the importance of a multidisciplinary and individualized treatment of FM (Blotman \& Branco, 2007). However, monetary constraints were reported in our study and can be associated with failures to follow a specific treatment regimen. Concerning the "individual strategies of coping" (cognitive and behavioural) these are useful in order to achieve a higher level of autonomy in the process of dealing with FM (Cunningham \& Jillings, 2006; Schaefer, 1997) and, in our sample, each of the participants have mentioned particular coping strategies they believe to be effective in the process of coping with FM.

The category "Perspectives about a new reality" included the following subcategories: "causal attributions", "perception of control", and "future perspectives". The "causal attributions" encompass the meanings built by participants about factors that may have contributed to the predisposition, triggering, and perpetuating of the syndrome. The process of meaning-making "causal attributions" is related to the human tendency to assess the world as predictable and controllable, namely in domain of health and illness (Ogden, 2004) and the absence of such attributions can be related to lower physical and psychosocial adjustment (Pimm, 1997). In our sample, all the participants formed some kind of attributions concerning predisposing, triggering, or perpetuating factors which support the relevance of giving a coherent meaning to their lives. Specifically, attributions acknowledging the psychosocial nature of predisposing factors of FM were commonly found which support previous studies (e.g. Hellström et al., 1999). That is, participants believe that adversity in their lives has contributed to their illness. Concerning triggering factors, the psychosocial attributions were also common, but in some cases there were no attributions made for the appearance of the first symptoms; physiological and mixed (physiological/psychosocial) were found as well, which partially support results found by Hellström et al. (1999). Regarding perpetuating factors, the predominance of psychosocial attributions was again found, followed by physical efforts, climate conditions and only one participant had not identified aggravating factors of FM. These results support those found by Schaeffer (1997), unlike those found by Hellström et al. (1999) who reported that FM patients considered their symptoms as unpredictable.

The category of "perception of control" represents participants' perceptions of their level of control over their illness. The narratives of participants have assumed various degrees of perceived control which can be placed in three mutually exclusive subcategories: "total perceived control" (7 participants), "intermediate perceived control" (7 participants), and "absence of perceived control" (6 participants) (table 3 ).

Joyce-Moniz and Barros (2005) stated that the individual position over a continuum of perceived control can have different consequences in terms of physical and emotional wellbeing. Concerning a perception of "total control", this is not always the most desirable representation, given that in some circumstances a perception of low control can be more adaptive, such as in those situations which are not objectively controllable (Ogden, 2004). Specifically with FM patients, the helplessness construct can be mentioned as conceptually close to "absence of perceived control" given that the former reflects the degree to which participants feel helpless in controlling pain and the course of FM (Palomino et al., 2007). In fact, helplessness, as the cognitive meaning of having FM, was found as playing a more central role in predicting depressive symptomatology than illness-related stressors, such as pain or disability (Palomino et al., 2007). 


\section{"PERCEPTION OF CONTROL"}

Total perceived control

"I control my illness. Undoubtedly. I control it in all senses. When I feel that intense pain I try to control, to move forward. I can feel the worst pain but if someone knocks on my door I welcome that person with a smile. Nobody realizes." (I8, 67 years old)

\section{Intermediate perceived control}

"For me fibromyalgia is something that I have to work on in order to deal with felt difficulties; when I'm not able I try to find support and better days will come. I know I'll have bad days, but those are only that: bad days." (I3, 32 years old)

\section{Absence of perceived control}

"I want to make certain activities and I am manipulated. I have someone who controls me...is fibromyalgia. I consider it as a living being. In my professional life I wish to hurry up and I'm not capable. 'She' commands more than me." (I19, 35 years old)

Table 3. Perception of control over FM.

Concerning the "future perspectives", this subcategory includes feelings and thoughts that people have about what will happen to them in relation to FM and, as the previous subcategory, is common to find participants discourses ranging from a very positive perspective to a very negative one. More specifically, we considered the following subcategories: positive perspective ( 3 participants), mixed perspective (5 participants), absence of future perspective ( 5 participants) and negative perspective (7 participants). Our results partially support those found by Hellstrom et al. (1999) and Söderberg and Lundman (2001). The first ones have stated mainly the prevalence of absence of future perspectives and the second ones have highlighted the positive perspectives despite the difficulties that need to be faced. These differences can be related to distinct levels of acceptance of FM in the various samples.

\subsection{Are the meanings of perceived control associated to patients' life stories and coping strategies, as well?}

In order to respond to the research question: "Are the meanings of perceived control associated to patients' life stories and coping strategies, as well?" four matrixes of intersecting subcategories were developed. Firstly, participants were grouped in three mutually exclusive subcategories of "perceived control" over FM considering their narratives on this topic. An even distribution was found across the subcategories "total perceived control" (7 participants), "intermediate perceived control" (7 participants), and "absence of perceived control" (6 participants). This result is consistent with previous literature (Joyce-Moniz \& Barros, 2005). Once subgroups were formed we were able to perform four intersection matrixes in order to respond our research question, namely: "Perceived control and Predisposing factors"; "Perceived control and Triggering factors"; "Perceived control and Perpetuating Factors"; and "Perceived control and Coping with fibromyalgia". 
Considering the intersection matrix of "perceived control and predisposing factors" (Table 4), participants who experience absence of control tend to present the highest prevalence of predisposing factors in their life stories, compared to participants with intermediate control, although this difference is not very accentuated. However, individuals in the subgroup "total control" have shown, clearly, the lowest prevalence of predisposing factors in their life stories.

\begin{tabular}{|c|c|c|c|c|c|c|}
\hline \multirow{2}{*}{ Subcategories } & \multicolumn{2}{|c|}{ Absence of Control } & \multicolumn{2}{|c|}{$\begin{array}{l}\text { Intermediate } \\
\text { Control }\end{array}$} & \multicolumn{2}{|c|}{ Total Control } \\
\hline & Part. & T.U. & Part. & T.U. & Part. & T.U. \\
\hline Adverse life events & 5 & 30 & 5 & 34 & 5 & 8 \\
\hline Significant losses & 3 & 7 & 5 & 20 & 5 & 8 \\
\hline Personality traits & 3 & 13 & 4 & 18 & 2 & 10 \\
\hline $\begin{array}{l}\text { Physical and/or } \\
\text { verbal violence }\end{array}$ & 4 & 12 & 2 & 8 & 3 & 10 \\
\hline Family conflicts & 4 & 7 & 3 & 10 & 2 & 9 \\
\hline $\begin{array}{l}\text { Excessive striving } \\
\text { for achievement at } \\
\text { work }\end{array}$ & 3 & 6 & 3 & 7 & 1 & 2 \\
\hline Emotional neglect & 5 & 7 & 2 & 2 & 0 & 0 \\
\hline $\begin{array}{l}\text { Nuclear family } \\
\text { psychosocial } \\
\text { problems }\end{array}$ & 3 & 10 & 3 & 3 & 1 & 1 \\
\hline Job dissatisfaction & 2 & 3 & 2 & 8 & 2 & 4 \\
\hline $\begin{array}{l}\text { Early assumption } \\
\text { of responsibility }\end{array}$ & 1 & 1 & 2 & 5 & 3 & 11 \\
\hline $\begin{array}{l}\text { Unsatisfying } \\
\text { relationships }\end{array}$ & 3 & 33 & 3 & 12 & 0 & 0 \\
\hline $\begin{array}{l}\text { History of sexual } \\
\text { abuse }\end{array}$ & 1 & 3 & 0 & 0 & 1 & 4 \\
\hline $\begin{array}{l}\text { Compensatory } \\
\text { overactive lifestyles }\end{array}$ & 1 & 5 & 1 & 1 & 0 & 0 \\
\hline
\end{tabular}

$N=20$. Part. (number of participants); T.U. (number of text units).

Table 4. Intersection matrix "Perceived Control and Predisposing Factors".

Regarding the identification of triggering factors, based on classification of perceived control, it must be noted that in only 12 of 20 participants $(60 \%)$ those factors were identified; although the smaller number of individuals, the lowest prevalence of triggering factors were found in the subgroup of "perceived total control" (Table 5). 


\begin{tabular}{lcccccc}
\hline & \multicolumn{2}{c}{ Absence of Control } & \multicolumn{2}{c}{$\begin{array}{c}\text { Intermediate } \\
\text { Control }\end{array}$} \\
\cline { 2 - 8 } Subcategories & Part. & T.U. & Part. & T.U. & Part. & T.U. \\
\cline { 2 - 8 } & $\mathbf{2}$ & - & $\mathbf{2}$ & - & $\mathbf{4}$ & - \\
$\begin{array}{l}\text { Not identified } \\
\begin{array}{l}\text { Extended period of } \\
\text { physical and/or }\end{array}\end{array}$ & $\mathbf{1}$ & 1 & $\mathbf{3}$ & 3 & $\mathbf{3}$ & 10 \\
$\begin{array}{l}\text { psychosocial stress } \\
\begin{array}{l}\text { Traumatic physical } \\
\text { experience }\end{array}\end{array}$ & $\mathbf{1}$ & 1 & $\mathbf{3}$ & 4 & $\mathbf{0}$ & 0 \\
$\begin{array}{l}\text { Painful injury } \\
\begin{array}{l}\text { Traumatic } \\
\text { emotional }\end{array}\end{array}$ & $\mathbf{1}$ & 1 & $\mathbf{2}$ & 3 & $\mathbf{0}$ & 0 \\
experience & $\mathbf{2}$ & 3 & $\mathbf{0}$ & 0 & $\mathbf{0}$ & 0 \\
\hline
\end{tabular}

$\mathrm{N}=$ 20. Part. (number of participants); T.U. (number of text units).

Table 5. Intersection matrix "Perceived Control and Triggering Factors".

In what concerns to perpetuating factors the results pattern was very similar to those obtained in predisposing factors. The participants with "total control" have shown the lowest prevalence of perpetuating factors in their life stories, followed by the "intermediate control" participants and, at last, the prevalence was the highest among participants with "absence of control" (Table 6).

\begin{tabular}{|c|c|c|c|c|c|c|}
\hline \multirow[t]{2}{*}{ Subcategories } & \multicolumn{2}{|c|}{ Absence of Control } & \multicolumn{2}{|c|}{$\begin{array}{l}\text { Intermediate } \\
\text { Control }\end{array}$} & \multicolumn{2}{|c|}{ Total Control } \\
\hline & Part. & T.U. & Part. & T.U. & Part. & T.U. \\
\hline Family relationships & 3 & 16 & 3 & 9 & 3 & 4 \\
\hline Sleep disturbances & 2 & 5 & 2 & 2 & 3 & 7 \\
\hline Catastrophic thoughts & 4 & 7 & 1 & 3 & 1 & 3 \\
\hline $\begin{array}{l}\text { Depressive/anxious } \\
\text { symptomatology }\end{array}$ & 3 & 13 & 2 & 2 & 1 & 9 \\
\hline Social withdrawal & 2 & 2 & 3 & 4 & 1 & 4 \\
\hline Low illness acceptance & 3 & 3 & 2 & 5 & 0 & 0 \\
\hline $\begin{array}{l}\text { Dysfunctional health } \\
\text { care-seeking } \\
\text { behaviour }\end{array}$ & 2 & 2 & 2 & 5 & 1 & 7 \\
\hline Somatic vigilance & 1 & 1 & 2 & 6 & 0 & 0 \\
\hline $\begin{array}{l}\text { Physical/psychosocial } \\
\text { stress }\end{array}$ & 1 & 3 & 1 & 1 & 1 & 3 \\
\hline
\end{tabular}

$\mathrm{N}=$ 20. Part. (number of participants); T.U. (number of text units).

Table 6. Intersection matrix "Perceived Control and Perpetuating Factors". 
On regard to the intersection matrix of coping with fibromyalgia and perceived control, participants with "absence of control" were those who less use therapeutic strategies and individual coping. In the groups of "intermediate control" and "total control" a similar use was found between them and contrasting with the former group. However, in the group "total control" more references to therapeutic strategies (T.U.) were found, which can suggest a higher involvement with that kind of strategies (Table 7).

\begin{tabular}{|c|c|c|c|c|c|c|c|}
\hline & \multirow[t]{2}{*}{ Subcategories } & \multicolumn{2}{|c|}{$\begin{array}{l}\text { Absence of } \\
\text { Control }\end{array}$} & \multicolumn{2}{|c|}{$\begin{array}{l}\text { Intermediate } \\
\text { Control }\end{array}$} & \multicolumn{2}{|c|}{ Total Control } \\
\hline & & Part. & T.U. & Part. & T.U. & Part. & T.U. \\
\hline \multirow{4}{*}{ 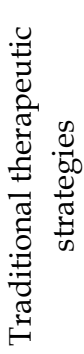 } & $\begin{array}{l}\text { Pharmacological } \\
\text { treatment }\end{array}$ & 5 & 10 & 6 & 6 & 4 & 7 \\
\hline & Psychotherapy & 1 & 2 & 5 & 7 & 2 & 2 \\
\hline & Physiotherapy & 5 & 7 & 2 & 3 & 1 & 1 \\
\hline & Physical exercise & 2 & 2 & 1 & 1 & 5 & 13 \\
\hline & $\begin{array}{l}\text { Complementary } \\
\text { therapies }\end{array}$ & 2 & 2 & 2 & 4 & 4 & 13 \\
\hline \multirow{2}{*}{ 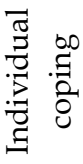 } & Cognitive coping & 1 & 1 & 6 & 14 & 5 & 10 \\
\hline & $\begin{array}{l}\text { Behavioural } \\
\text { coping }\end{array}$ & 1 & 5 & 4 & 10 & 5 & 12 \\
\hline
\end{tabular}

$\mathrm{N}=$ 20. Part. (number of participants); T.U. (number of text units).

Table 7. Intersection matrix "Perceived Control and Coping with Fibromyalgia"

In general, results suggest that individuals with the lowest perceived control on FM tend to report life stories with a higher prevalence of predisposing, triggering, and perpetuating factors and lower use of coping strategies with FM (use of therapies and individual coping), as well. One of the possible explanations can be that life stories with a large number of adverse events could have contributed to a sense of victimization and helplessness, promoting the development of low perceived control meanings facing life experiences in general, and the experience of FM, in particular (Quartilho, 2001a). It must be noted that the association between lower perceived control and higher prevalence of perpetuating factors suggests that these participants are likely to experience worse levels of health-related quality of life. However, additional studies are needed in order to confirm this. The use of selfreport measures could be useful in order to identify these aspects, such as the Rheumatology Attitudes Index (RAI) - 5-item Helplessness Subscale (DeVellis \& Callahan, 1993; cit. in Palomino et al., 2007) which assesses helplessness in controlling pain and the course of FM, simultaneously with measures of FM severity (Wilke, 2009; Wolfe et al., 2010). 
Finally, perceived control was associated to prevalence of strategies to cope with FM (therapeutic and individual coping). As stated by Ogden (2004), the belief of being able to control the illness tends to be associated to the maintenance of healthy behaviours and elimination of harmful ones.

\section{Conclusions}

The results have supported the categorization of three types of psychosocial factors proposed in literature as having a role in origin and maintenance of FM syndrome. Moreover, specific themes within each one of categories could be identified. As shown in patients' life stories the susceptibility to FM may be based in developmental factors which constitute predisposing factors to it. Moreover, FM symptoms often begin after a period of physical or psychosocial adversity. Finally, some factors may contribute to the perpetuation of symptoms and disability in FM. The clinical implications of these data refer to the importance of promoting changes on psychosocial perpetuating factors in order to improve health-related quality of life in these patients. Furthermore, the differentiation of FM patients in subgroups based on the relative weight of predisposing, triggering, and perpetuating factors could be useful in tailoring interventions adapted to particular needs of each subgroup. On the other hand, the meanings of patients living with FM shed light on their inner experiences which can lead health-care providers in the process of communicating more efficiently with these patients. We focus on the relevance of narrative therapy with FM patients in order to promote an integration of life stories with current experiences allowing a more complex cognitive and emotional perspective on their lives. Future research should focus on life stories in patients suffering from other chronic medical conditions, and even healthy individuals, in order to better understand similarities and differences with narratives of FM patients. On the whole, our results support the relevance of a biopsychosocial approach in assessment and intervention with FM patients, given the multifactorial genesis and maintenance of FM syndrome, which require an articulation of Psychology contributions with other health-care disciplines.

\section{References}

Aïni, K., Curelli-Chereau, A., \& Antoine, P. (2010). L'expérience subjective de patients avec une fibromyalgie: analyse qualitative [The subjective experience of patients living with fibromyalgia: A qualitative analysis]. Annales médico-psychologiques, Vol.168, No.4, pp. 255-262.

Arnold, L. M., Crofford, L. J., Mease, P. J., Burgess, S. M., Palmer, S. C., Abetz, L., et al. (2008). Patient perspectives on the impact of fibromyalgia. Patient Education $\mathcal{E}$ Counseling, Vol.73, No.1, pp. 114-120.

Asbring, P. (2001). Chronic illness - a disruption in life: Identity-transformation among women with chronic fatigue syndrome and fibromyalgia. Journal of Advanced Nursing, Vol.34, No.3, pp. 312-319.

Blotman, F., \& Branco, J. (2007). Fibromyalgia: Daily aches and pain, Éditions Privat, Toulouse. 
Cunningham, M., \& Jillings, C. (2006). Individuals' descriptions of living with fibromyalgia. Clinical Nursing Research, Vol.15, No.4, pp. 258-273.

Eich, W., Hartmann M., Muller, A., \& Fischer, H. (2000). The role of psychosocial factors in fibromyalgia syndrome. Scandinavian Journal of Rheumatology, Suppl. 113, pp. 30-31.

Garcia-Campayo, J., \& Alda, M. (2004). La vivencia de la sexualidad en pacientes con fibromialgia: Un estudio cualitativo [Experience of sexuality in fibromyalgia patients: A qualitative study]. Archivos de Psiquiatria, Vol.67, No.3, pp. 157-168.

Gauer, J. S. (2009). Fibromyalgia in the workplace: Exploring the impact of chronic pain upon whitecollar workers. Unpublished doctoral dissertation. Capella University.

Joyce-Moniz, L., \& Barros, L. (2005). Psicologia da doença para cuidados de saúde [Psycholoy of illness for health care practice], Edições Asa, Porto.

Leventhal, H., Benyamini, Y., Brownlee, S., Diefenbach, M., Leventhal, E., Patrick-Miller, L. et al. (1997). Illness representations: Theoretical foundations. In: Perceptions of health and illness: Current research and applications, K. Petrie, \& J. Weinman (Eds.), pp. 1946, Harwood Academic Publishers, Amsterdam.

Leventhal, H., Meyer, D., \& Nerenz, D. (1980). The common sense representation of illness danger. In: Medical Psychology: Vol.2, S. Rachman (Ed.), pp. 7-30, Pergamon: New York.

Liedberg, G. M., \& Henriksson, C. M. (2002). Factors of importance for work disability in women with fibromyalgia: an interview study. Arthritis and Rheumatism, Vol.47, No.3, pp. 266-274.

Hagger, M., \& Orbell, S. (2003). A meta-analytic review of the common-sense model of illness representations. Psychology and Health, Vol.18, No.2, pp. 141-184.

Hellström, O., Bullington, J., Karlsson, G., Lindqvist, P., \& Mattsson, B. (1999). A phenomenological study of fibromyalgia. Patient perspectives. Scandinavian Journal of Primary Health Care, Vol.17, pp. 11-16.

Ogden, J. (2004). Psicologia da Saúde [Health Psychology] (2a ed.), Climepsi Editores, Lisboa.

Oliveira, P. (2008). Variáveis psicossociais e fibromialgia [Psychosocial variables and fibromaylgia]. Unpublished doctoral dissertation. Faculty of Psychology and Educational Sciences of University of Porto, Portugal.

Palomino, R., Nicassio, P., Greenberg, M., \& Medina, E. (2007). Helplessness and loss as mediators between pain and depressive symptoms in fibromyalgia. Pain, Vol.129, pp. 185-194.

Pimm, T. (1997). Self regulation and psycho-educational interventions for rheumatic disease. In: Perceptions of health and illness: Current research and applications, $\mathrm{K}$. Petrie, \& J. Weinman (Eds.), pp. 349-378, Harwood Academic Publishers: Amsterdam.

Quartilho, M. (2001a). Cultura, medicina e psiquiatria: Do sintoma à experiência [Culture, medicine, and psychiatry: From symptom to experience], Quarteto Editora, Coimbra.

Quartilho, M. (2001b). Dor crónica: Aspectos psicológicos, sociais e culturais [Chronic pain: Psyhcological, social and cultural dimensions]. Acta Reumatológica Portuguesa, Vol.26, pp. 255-262. 
Quartilho, M. (2004). Fibromialgia: Consenso e controvérsia [Fibromyalgia: Consensus and controversy]. Acta Reumatológica Portuguesa, Vol.29, pp. 111-129.

Schaefer, K. (1995). Struggling to maintain balance: A study of women living with fibromyalgia. Journal of Advanced Nursing, Vol.21, pp. 95-102.

Schaefer, K. (1997). Health patterns of women with fibromyalgia. Journal of Advanced Nursing, Vol.26, pp. 565-571.

Scharloo, M., \& Kaptein, A. (1997). Measurement of illness perceptions in patients with chronic somatic illness: A review. In: Perceptions of health and illness: Current research and applications, K. Petrie, \& J. Weinman (Eds.), pp. 103-154, Harwood Academic Publishers, Amsterdam.

Schmidt, K. M. (2008). The couple as a pair bond and the lived experience of dyadic coping with fibromyalgia: A phenomenological study. Unpublished doctoral dissertation. Capella University.

Sim, J., \& Madden, S. (2008). Illness experience in fibromyalgia syndrome: A metasynthesis of qualitative studies. Social Science \& Medicine, Vol.67, No.1, pp. 57-67.

Söderberg, S., \& Lundman, B. (2001). Transitions experienced by women with fibromyalgia. Health Care for Women International, Vol.22, pp. 617-631.

Söderberg, S., Strand, M., Haapala, M., \& Lundman, B. (2003). Living with a woman with fibromyalgia from de perspective of the husband. Journal of Advanced Nursing, Vol.42, No.2, pp. 143-150.

Strauss, A.L., \& Corbin, J.M. (1998). Basics of qualitative research: Techniques and procedures for developing grounded theory (2nd ed.), Sage, Thousand Oaks, CA.

Undeland, M., \& Malterud, K. (2007). The fibromyalgia diagnosis - hardly helpful for the patients? Scandinavian Journal of Primary Health Care, Vol.25, No.4, pp. 250255.

Van Houdenhove, B., \& Egle, U. (2004). Fibromyalgia: A stress disorder? Piecing the biopsychosocial puzzle together. Psychotherapy and Psychosomatics, Vol.73, No.5, pp. 267-275.

Van Houdenhove, B., Egle, U., \& Luyten, P. (2005). The role of life stress in fibromyalgia. Current Rheumatology Reports, Vol.7, pp. 365-370.

Wilke, W. (2009). New developments in the diagnosis of fibromyalgia syndrome: Say goodbye to tender points? Cleveland Clinic Journal of Medicine, Vol.76, No.6, pp. 345352.

Wolfe, F., Claw, D., Fitzcharles, M., Goldenberg, D., Katz, R., Mease, P. et al. (2010). The American College of Rheumatology preliminary diagnostic criteria for fibromyalgia and measurement of symptom severity. Arthritis Care $\mathcal{E}$ Research, Vol.62, No.5, pp. 600-610.

Wolfe, F., Smythe, H., Yunus, M., Bennett, R., Bombardier, C., Goldenberg, D. et al. (1990). The American College of Rheumatology 1990 criteria for the classification of fibromyalgia: Report of the multicenter criteria committee. Arthritis and Rheumatism, Vol.33, No.2, pp. 160-172. 
Yardley, L. (1997). Introducing material-discursive approaches to health and illness, In: Material discourses of health and illness, L. Yardley (Ed.), pp. 1-24, Routledge, London. 


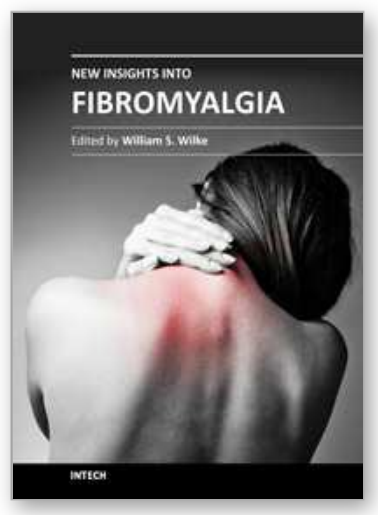

\author{
New Insights into Fibromyalgia \\ Edited by Dr. William S. Wilke
}

ISBN 978-953-307-407-8

Hard cover, 216 pages

Publisher InTech

Published online 05, January, 2012

Published in print edition January, 2012

Given the potential problems that can obscure any scientific enterprise, inconsistent results across studies are bound to occur. How are we to decide what is true? Let's turn to philosophy for a reasonable answer. The mathematician-philosopher Bertrand Russell approached a similar problem in his monograph The Problems of Philosophy (Russell B, 1912). He addressed the following question: How do we know that anything is "real"? Is the only reality subjective and simply in our minds, as Bishop Berkley challenged, or can we mostly believe the objective reality? His pragmatic answer: All possibilities may be true, but when the preponderance of evidence indicates that objective reality and knowledge are the most probable case, go with it. If the preponderance of all evidence about the clinical description of fibromyalgia and it's pathogenic mechanisms and treatment strategies indicate a highly probable interrelated hypothesis, go with it. The direction of the literature on the whole trumps the less likely tangents. At the same time, remember Bertrand Russell and his pragmatic answer, and keep an open mind.

\title{
How to reference
}

In order to correctly reference this scholarly work, feel free to copy and paste the following:

Paula J. Oliveira and Maria Emîlia Costa (2012). Psychosocial Factors in Fibromyalgia: A Qualitative Study on Life Stories and Meanings of Living with Fibromyalgia, New Insights into Fibromyalgia, Dr. William S. Wilke (Ed.), ISBN: 978-953-307-407-8, InTech, Available from: http://www.intechopen.com/books/new-insights-intofibromyalgia/psychosocial-factors-in-fibromyalgia-a-qualitative-study-on-life-stories-and-meanings-of-living-with

\section{INTECH}

open science | open minds

\section{InTech Europe}

University Campus STeP Ri

Slavka Krautzeka 83/A

51000 Rijeka, Croatia

Phone: +385 (51) 770447

Fax: +385 (51) 686166

www.intechopen.com

\section{InTech China}

Unit 405, Office Block, Hotel Equatorial Shanghai

No.65, Yan An Road (West), Shanghai, 200040, China

中国上海市延安西路65号上海国际贵都大饭店办公楼 405 单元

Phone: +86-21-62489820

Fax: $+86-21-62489821$ 
(C) 2012 The Author(s). Licensee IntechOpen. This is an open access article distributed under the terms of the Creative Commons Attribution 3.0 License, which permits unrestricted use, distribution, and reproduction in any medium, provided the original work is properly cited. 